\title{
EFFECT OF WEATHERING ON PHYSICALAND MECHANICAL PROPERTIES OF HYBRID NANOCOMPOSITE BASED ON POLYETHYLENE, WOODFLOUR AND NANOCLAY
}

\author{
Amir Eshraghi $^{1, \star}$, Habibollah Khademieslam ${ }^{1}$, Ismaeil Ghasemi ${ }^{2}$
}

\begin{abstract}
Wood plastic composites have received increasing attention during the last decades, because of many advantages related to their use. However the durability of Wood plastic composites after ultraviolet exposure has become a concern. In this research, hybrid nanocomposites of polyethylene and woodflour with different concentrations of nanoclay were fabricated using melt compounding followed by injection molding. Specimens were exposed for $2000 \mathrm{~h}$ to ultraviolet radiation and moisture cycling in a laboratory weathering device to simulate the effects of exposure to sunlight and rain. Physical and mechanical properties of the nanocomposites were evaluated, before and after weathering. The results indicated that the water absorption of wood plastic composites increased after weathering but nanoclay reduced the intensity of weathering to some extent, through decreasing of water absorption. Also results showed that weathering decreased modulus of elasticity values, however good dispersion of clay layers resulted in fewer drop of modulus of elasticity values. Fourier transform infrared spectroscopy showed that lowest carbonyl index is related to the nano wood plastic composites with $2 \mathrm{wt} \%$ nanoclay. Also $\mathrm{X}$-Ray diffraction patterns revealed that intercalation morphology has been formed for nano particles.
\end{abstract}

Keywords: Carbonyl index, Fourier transform infrared spectroscopy, modulus of elasticity, Populus deltoides, water absorption, wood plastic composites, X-Ray diffraction.

\section{INTRODUCTION}

Using lignocellulosics as fillers and reinforcements in thermoplastics has been gaining acceptance in commodity plastics applications in the past few years. The advantages of using a bio based component in thermoplastic composites is non abrasive, low in cost, widely available, sustainable, high filling levels possible, high specific properties, lower density per weight of raw material, flexible and recyclable (Khonsari et al. 2015). However cellulosic fibers have some disadvantages, such as lower processing temperature, and incompatibility between the hydrophilic fibers and hydrophobic polymers. Also, moisture absorption of the cellulosic fibers has undesirable effects on the properties of composites (Belgacem et al. 1994). Therefore the use of composites by the construction industry has resulted in concern about the durability of these products when exposed to outdoor environments. On the one hand, the durability of WPC after ultraviolet exposure is very important (Stark and Matuana 2004). The weathering resistance of WPCs is generally less than other polymer based composites, and dimensional changes caused by outdoor exposure are major problems for their use outdoors (Stark et al. 2003). Some researchers studied accelerated weathering of WPCs with combinative ultraviolet radiation and water spray. They concluded that water absorption and thickness swelling of the composites were increased after accelerated weathering (Adhikary et al. 2009). On the other hand, weathering causes WPCs lose their mechanical properties. Moisture penetration into the WPC degrades the wood-polymer interface, which in turn causes loss of strength as the stress transfer from matrix to fiber becomes less efficient.

\footnotetext{
${ }^{1}$ Department of Wood and Paper Science and Technology, Science \& Research Branch, Islamic Azad University, Tehran, Iran. ${ }^{2}$ Iran Polymer and Petrochemical Institute, Tehran, Iran. 
Scientists exposed high density polyethylene (HDPE) composites filled with $40 \mathrm{wt} \%$ wood fiber to a water bath for $2000 \mathrm{~h}$. They concluded that WPCs experienced $22 \%$ decrease in flexural strength (Stark 2001). In the last years, the addition of materials at a nanometric scale into polymer matrices has increased in a remarkable way. Many researches of nanoparticles have been focused on modified nanoclays. These are composed of organic modified laminar silicate structures which allow obtaining a hybrid organic-inorganic structure. Montmorillonite based clays (MMT) offer high interest from an industrial point of view since the use of small amounts of them is enough to improve the overall properties of a polymer matrix at a relatively low cost (Pascual et al. 2009). These improvements include high moduli; increased tensile strength and thermal stability; decreased gas permeability, improved flammability properties, decrease in water absorbance and increased biodegradability of polymers (Ashori and Nourbakhsh 2009). However it seems that nanoparticles have an accelerating effect acting as catalysts to HDPE photo-oxidation. Scientists studied different series of HDPE nanocomposites which prepared by melt mixing, containing $2,5 \mathrm{wt} \%$ of multiwall carbon nanotubes, pristine and modified montmorillonite, and $\mathrm{SiO}_{2}$ nanoparticles. From FTIR study it was found that $\mathrm{SiO}_{2}$ and organically modified montmorillonite cause a serious effect on HDPE during UV degradation and new chemical compounds containing carbonyl, vinyl and hydroxyl groups were formed meaning that nanoparticles may accelerate the photo-oxidation of HDPE (Grigoriadou et al. 2011). The objective of this work is to investigate the influence of nanoclay loading level on mechanical property and water resistance of the nanocomposites before and after weathering. To interpret these properties the morphology of the nanoparticles was evaluated.

\section{MATERIALS AND METHODS}

\section{Materials}

HDPE with a density of $0,952 \mathrm{~g} / \mathrm{ml}$ and MFR $\left(190^{\circ} \mathrm{C} / 2,16 \mathrm{~kg}\right)$ of $18 \mathrm{~g} / 10 \mathrm{~min}$ as polymer matrix, poplar (Populus deltoides) as cellulosic material ( $80 \mathrm{mesh}$ ), maleic anhydride grafted polyethylene (MAPE) with a density of $0,965 \mathrm{~g} / \mathrm{cm}^{3}$ (MFI $7 \mathrm{~g} / 10 \mathrm{~min}$, grafted maleic anhydride $1 \mathrm{wt} \%$ ) as coupling agent and natural montmorillonite modified with dimethyl-dehydrogenated tallow-ammonium chloride salt (cloisite $15 \mathrm{~A}$ with $\mathrm{d}$ spacing of $31,5 \mathrm{~A}^{\circ}$ and modifier concentration of $125 \mathrm{meq} / 100 \mathrm{~g}$ clay) as reinforcement were used.

\section{Method}

\section{Sample Preparation}

Before sample preparation, woodflour was dried in an oven at $(70 \pm 5)^{\circ} \mathrm{C}$ for $24 \mathrm{~h}$. Then HDPE, woodflour, nanoclay and MAPE were weighed and bagged according to formulations given in Table 1 . Mixing was carried out in a Haake internal mixer (sys 90, USA) equipped with cam blade at $150^{\circ} \mathrm{C}$ and $60 \mathrm{rpm}$. First the HDPE was fed into mixing chamber, after melting of HDPE, nanoclay and coupling agent were added. After mixing for $5 \mathrm{~min}$, the woodflour was fed into the system. The total mixing time was $10 \mathrm{~min}$. The compounded materials were then grinded to prepare the granules using a pilot scale grinder (WIESER, WGLS 200/200 model). The resulting granules were dried at $105^{\circ} \mathrm{C}$ for $24 \mathrm{~h}$. Test specimens were prepared by an injection molding machine (Imen Machine, IRAN) at $190^{\circ} \mathrm{C}$. The specimens were stored under controlled conditions $\left(50 \%\right.$ relative humidity and $\left.23^{\circ} \mathrm{C}\right)$ for at least $40 \mathrm{~h}$ prior to testing.

Table 1. Composition of the studied formulations.

\begin{tabular}{|l|c|c|c|c|}
\hline Sample Code & $\begin{array}{c}\text { HDPE } \\
(\mathrm{wt} \%)\end{array}$ & $\begin{array}{c}\text { Woodflour } \\
(\mathrm{wt} \%)\end{array}$ & $\begin{array}{c}\text { Nanoclay } \\
(\mathrm{wt} \%)\end{array}$ & MAPE (wt\%) \\
\hline 30W & 67 & 30 & 0 & 3 \\
\hline 30W2N & 65 & 30 & 2 & 3 \\
\hline 30W4N & 63 & 30 & 4 & 3 \\
\hline
\end{tabular}




\section{Testing and analysis}

\section{Weathering}

Composite specimens were weathered using an Atlas Electric Devices (xenon-arc type light exposure apparatus) according to ASTM D 2565. Specimens were rotated by the weatherometer at 1 $\mathrm{rpm}$ around a spray nozzle and UV source. The device was set to provide $102 \mathrm{~min}$ of light followed by $18 \mathrm{~min}$ of light and water spray, exposing one side of the specimens to direct light and water spray while subjecting both sides to high levels of humidity. The irradiance was maintained at 41,5 $\pm 2,5$ (W/ $\mathrm{m}^{2}$ ). The black panel temperature was maintained at $63 \pm 2^{\circ} \mathrm{C}$. Specimens were placed on racks without backing and at the end of $2000 \mathrm{~h}$ selected specimens were removed for testing.

\section{Fourier transform infrared spectroscopy}

FTIR spectroscopy was conducted on a BRUKER Vertex- 89 spectrometer to provide knowledge of functional groups present at the composite surface before and after weathering. For each sample, 16 scans were recorded in absorbance units from 4000 to $600 \mathrm{~cm}^{-1}$. Spectra were obtained using attenuated total reflectance (ATR). Carbonyl index was calculated using the following equations:

$$
\text { Carbonyl Index }=\frac{I_{1715}}{I_{2916}} \times 100
$$

where I represents the peak intensity. The peak intensities at $1715 \mathrm{~cm}^{-1}$ corresponds to carbonyl groups that were normalized using the peak at $2916 \mathrm{~cm}^{-1}$, which corresponds to alkane $\mathrm{CH}$ stretching vibrations of the methylene groups. This peak was chosen as a reference peak because it changed the least during weathering.

\section{X-Ray Diffraction}

The degrees of clay intercalation in WPCs were evaluated by X-ray diffraction (XRD) analysis. XRD measurements were carried out in a Philips diffractometer (Xpert MPD, Holland) using $\mathrm{CuK}_{\alpha}$ $\left(\lambda=1,78 \mathrm{~A}^{\circ} ; 40 \mathrm{kV}, 30 \mathrm{~mA}\right)$ radiation at a scanning rate of $1^{\circ} / \mathrm{min}$ with an angle ranging from $1^{\circ}$ to $10^{\circ}$.

\section{Water absorption}

Water absorption tests were carried out according to ASTM D 7031-04. Three specimens for each formulation were dried in an oven $\left(102 \pm 2^{\circ} \mathrm{C}\right.$ for $\left.24 \mathrm{~h}\right)$. The samples were weighed prior to immersion in the water. Afterwards, the dried specimens were placed in distilled water and kept at room temperature. The weight of the immersed samples was determined after 30 days. Water absorption of the samples was determined based on the following equation:

$$
W A_{t}=\frac{W_{t}-W_{0}}{W_{0}} \times 100
$$

Where $\mathrm{WA}_{\mathrm{t}}$ is the water absorption at time $\mathrm{t}, \mathrm{W}_{\mathrm{o}}$ is the oven dried weight, and $\mathrm{W}_{\mathrm{t}}$ is the weight of specimen at a given immersion time $t$.

\section{Modulus of Elasticity}

The tensile modulus tests were measured according to the ASTM D638, using an Instron machine (Model 1186, England). The tests were performed at crosshead speeds of $5 \mathrm{~mm} / \mathrm{min}$. For each treatment level, three replications were tested. 


\section{Statistics}

To determine the effect of weathering on the physical and mechanical properties, student's twotailed t-tests were carried out at $\alpha=0,05$ for each sample, testing the data for significant differences due to weathering.

\section{RESULTS AND DISCUSSION}

\section{Water Absorption}

The results of water absorption (after 30 days immersion) for WPCs with different percentages of nanoclay were shown in Figure 1. Generally the hydrophilic nature of woodflour is responsible for the water absorption of the composites. The water absorption of composites decreased with incorporation of nanoclay. The higher the amount of nanoclay, the lower was the water absorption (Samariha et al. 2015). Organically modified clay increases the tortuous path for water transport and as a result water diffusivity will decrease (Alexandre et al. 2006). Barrier property of nanocomposite was studied and it was stated that nanoclay hinders the permeation of water through the composite (Kord et al. 2011). Moreover, the void spaces in the woodflour were occupied by the polymer and nanoclay. Hence the available space for water absorption will decrease. The higher the nanoclay, the lower is the available space to hold the water. Both the tortuous path and reduction in void space decrease the water absorption capacity of WPC. Hence, nanoWPCs showed lower water absorption compared to WPCs. As can be seen from Figure 1, the water absorption of all samples increased after weathering. Comparing the water absorption values before and after weathering it can be seen that, WPCs increased $26,1 \%$ while nanoWPCs with 2 and $4 \mathrm{wt} \%$ nanoclay increased $24,1 \%$ and $19,9 \%$; respectively. These results imply that weathering affected the water absorption of WPCs more than that of nanoWPCs. The published papers revealed that weathering increases the wettability of the composites (Colom et al. 2003) and also showed that photo-degradation of HDPE can be accelerated by metal ions which can be found in nanoparticles and finally resulted in more increasing of water absorption of composites (Grigoriadou et al. 2011). Therefore, it is expected that UV exposure of WPCs containing nanoclay resulted in more severe weathering than WPCs and subsequently further increasing of water absorption. But our results indicated that increase of water absorption of nanoWPCs containing $4 \mathrm{wt} \%$ nanoclay caused by weathering, is less than that of WPCs. This is consistent with the results of other researchers. They also stated that the nanoclay plays a greater role in decreasing water absorption than in increasing weathering (Eshraghi et al. 2013).

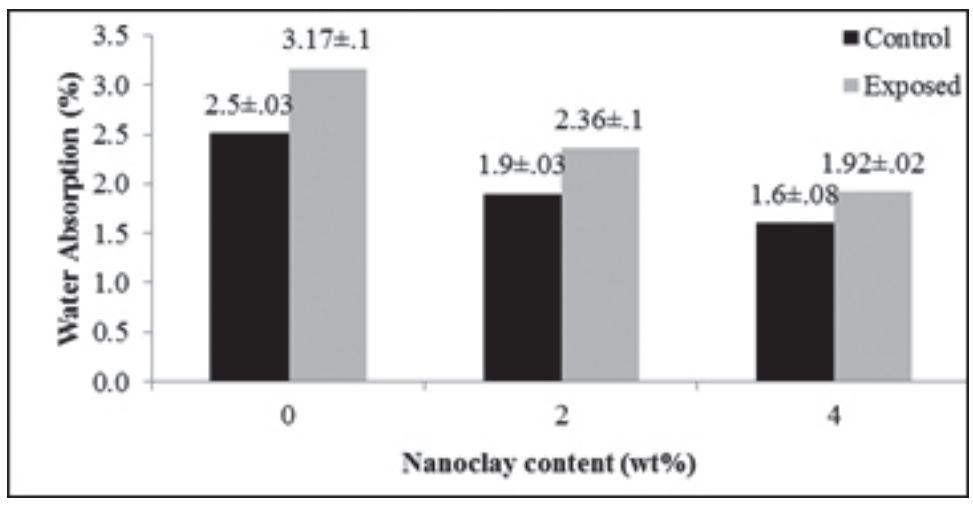

Figure 1. Effect of nanoclay on water absorption (30 days) of exposed and control composites.

The structural changes of WPCs with and without nanoclay were investigated via FTIR spectroscopy before and during the weathering. The area that showed alterations corresponded to the carbonyl groups $\left(-\mathrm{C}=\mathrm{O}, 1700-1800 \mathrm{~cm}^{-1}\right)$ (Figure $2 \mathrm{a}$ and $\left.\mathrm{b}\right)$. WPC as well as nanoWPC gave expanded 
peak in this area, indicating the oxidation of the materials. The intensity of this peak increased during ultraviolet radiation. Some reports stated that the intensity of carbonyl peak increases continuously with the increasing of illumination time. Moreover, it was observed that the band at $1700-1800 \mathrm{~cm}^{-1}$ broadened as the experiment was carried on. This is due to the appearance of multiple oxidation products as $\gamma$-lactones, esters, carboxylic acids and conjugated ketones (Vazquez et al. 2006, Roy et al. 2009). Comparing the carbonyl peak areas, it can be seen that after same exposure time the strongest carbonyl peak is related to nanoWPCs with $4 \mathrm{wt} \%$ nanoclay, demonstrating that the use of $4 \mathrm{wt} \%$ of nanoclay results in more weathered WPCs. Also it was found that after the same exposure time the carbonyl peak of nanoWPCs with $2 \mathrm{wt} \%$ nanoclay content has grown less than other peaks meaning that less oxidation has occurred. It seems that this is due to intercalation morphology and good dispersion of clay layers and consequently lower water absorption (Figure 5). Some reports revealed the effect of morphology of nanoclay on water absorption. They stated that the water absorption affected by morphology of nanocomposite and also higher order of intercalation results in less water absorption (Ghasemi and Kord 2009). Also scientists noted that the presence of moisture (by accelerating the oxidation reactions) greatly contributes to more degradation of physical and mechanical properties of WPC during weathering (Stark 2006). Therefore it can be concluded that better dispersion of clay layers contribute to less water absorption and consequently less oxidation and finally less growing of carbonyl peak.

(a)

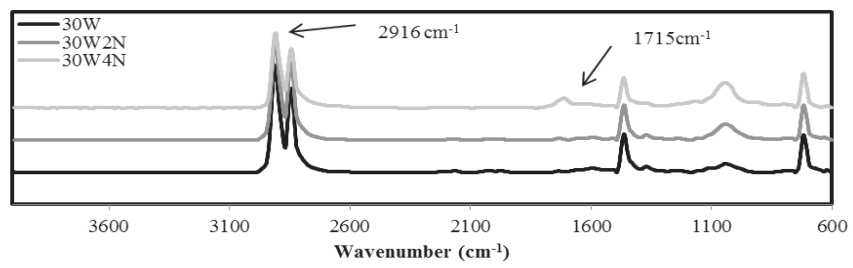

(b)

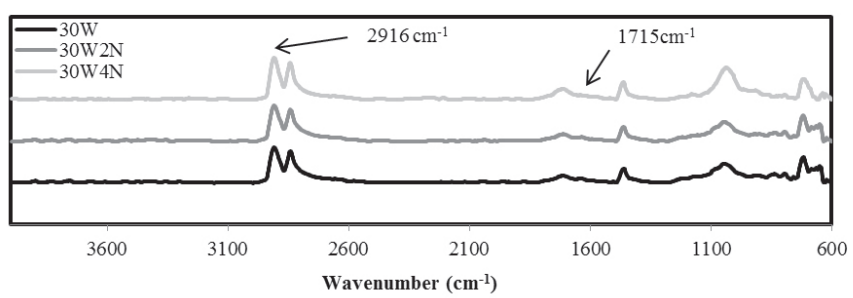

Figure 2. FTIR spectra of (a) control and (b) exposed composites with (2 and 4wt $\%$ ) and without nanoclay.

Figure 3 shows that the carbonyl index of all samples increases upon exposure time and it can be observed that carbonyl index of the samples contain $2 \mathrm{wt} \%$ nanoclay is less than that of the samples with $4 \mathrm{wt} \%$ nanoclay after $2000 \mathrm{~h}$ of weathering. Also it can be seen that the carbonyl index of nanoWPCs (with $2 \mathrm{wt} \%$ nanoclay) is less than WPCs during exposure time. Therefore, it can be concluded that addition of $2 \mathrm{wt} \%$ of nanoclay to WPCs causes decreasing of carbonyl index significantly. 


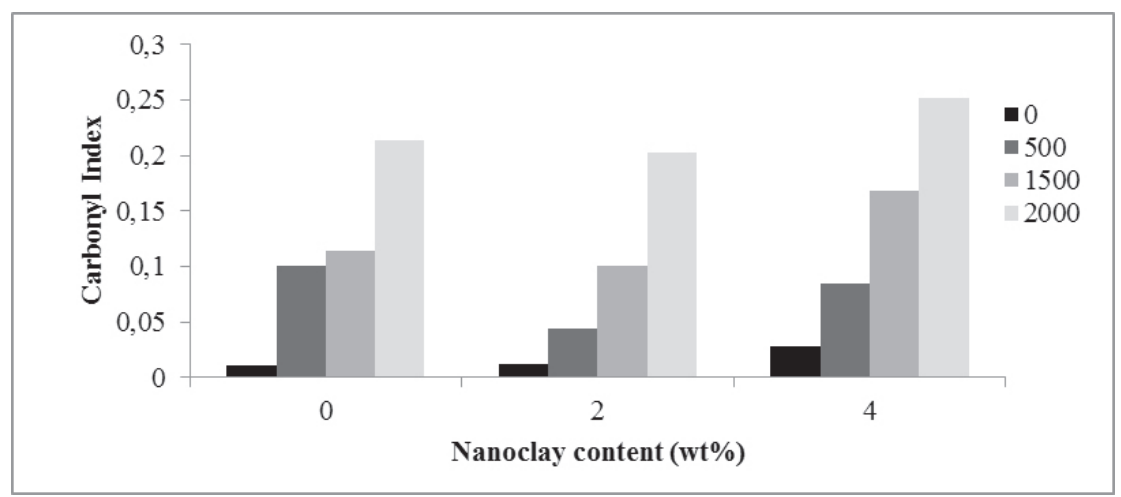

Figure 3. Effect of nanoclay on the carbonyl index during 500, 1500 and $2000 \mathrm{~h}$ of exposure.

\section{Modulus of Elasticity}

Figure 4 shows that the addition of nanoclay increases MOE values of the WPCs. MOE values increased with nanoclay loading up to $2 \mathrm{wt} \%$, beyond that the values decreased. The observed higher values might be due to the higher dispersion of silicate layers of nanoclay in the polymer matrix. Besides the nanoclay contained some hydrocarbon portions which facilitated the interaction between woodflour and polymer matrix. All these suggested an improvement in adhesion between polymer, wood and clay. The nanoWPCs thus exhibited better properties over WPCs. The inclusion of organoclay resulted in the improvement in mechanical properties which were reported by other investigators (Lee and Kim 2009). The decrease in MOE values of nanoWPC with $4 \mathrm{wt} \%$ nanoclay might be attributed to the migration of clay to the interface between woodflour and polymer. The presence of high amount of fibre and its interface with polymer might have reduced the reinforcement effect of clay. Similar observation was reported by other researchers (Candan and Akbulut 2015). Another reason for decrease in MOE could be related to the dispersion and homogeneity of the media (Samariha et al. 2015). Also Figure 4 shows the drop in MOE values after $2000 \mathrm{~h}$ of weathering for all WPCs with and without nanoclay content, however the loss in MOE values was 10,4\% for the WPCs and 9,7\% and 8,5\% for nanoWPCs with 2 and $4 \mathrm{wt} \%$ nanoclay content, respectively. Clearly it is observed that after weathering, the MOE values of nanoWPCs dropped less than that of WPCs. As mentioned above, metal ions in nanoparticles accelerate photo-degradation of HDPE (Grigoriadou et al. 2011). Also it has been observed that weathering has an adverse effect on both physical and mechanical properties of polymers and lignocellulosics (Lundin et al. 2004). Therefore it is expected that the mechanical properties of nanoWPCs degraded more than WPCs. However it should be noted that the negative effect of nanoclay on weathering is balanced by two phenomena. Dispersion of nanoclay as a positive effect could enhance the MOE (Hemmasi et al. 2010), and also barrier properties of nanoclay decrease the water penetration into nanocomposite materials (Ashori and Nourbakhsh 2011) and then less drop of MOE occurs by decreasing of water absorption. Scientists stated that the mechanical properties of woodflour filled polymer composites are negatively affected by moisture (Stark et al. 2003). Therefore it can be concluded that the negative effect of weathering that is accelerated by nanoclay can be neutralized by good dispersion and barrier property of nanoclay. 


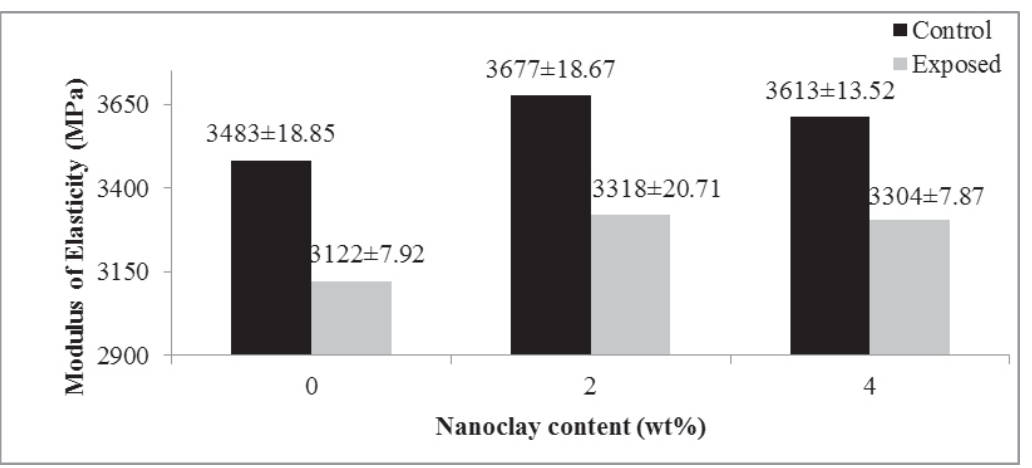

Figure 4. Effect of nanoclay on modulus of elasticity of exposed and control composites.

The X-ray patterns for modified organoclay and hybrid nanocomposites with different levels of nanoclay at $3 \mathrm{wt} \%$ MAPE are shown in Figure 5. The interlayer spacing was calculated according to Bragg's law,

$$
n \lambda=2 d \sin \theta
$$

In this figure, $2 \theta=2,80^{\circ}$ is related to neat clay with basal spacing of $31,5 \mathrm{~A}^{\circ}$. In the sample with $2 \mathrm{wt} \%$ nanoclay, the peak was shifted to a lower angle $\left(2 \theta=2,25^{\circ} ; \mathrm{d}\right.$-spacing $\left.=39,18 \mathrm{~A}^{\circ}\right)$ which implies the formation of the intercalation morphology. The peak of $4 \mathrm{wt} \%$ nanoclay was appeared at $2 \theta=2,35$; $\mathrm{d}$-spacing $=37,6 \mathrm{~A}^{\circ}$. These data show that the order of intercalation is higher for $2 \mathrm{wt} \%$ of nanocaly than that of $4 \mathrm{wt} \%$. It seems this is because of the limited value of MAPE in the nanoWPCs. The shifting of the peak to lower angle indicated an increase in interlayer spacing of silicate layers. The polymer chains were intercalated into the silicate nanolayers. A shifting of diffraction peak to the lower angle for the clay based HDPE nanocomposite was reported in the literature (Faruk and Matuana 2008). The observed peak at $4 \mathrm{wt} \%$ of nanoclay might be due to agglomeration of some clay. The shifting of the peak from higher diffraction angle to lower diffraction angle was reported by Lee and Kim (Lee and Kim 2009).

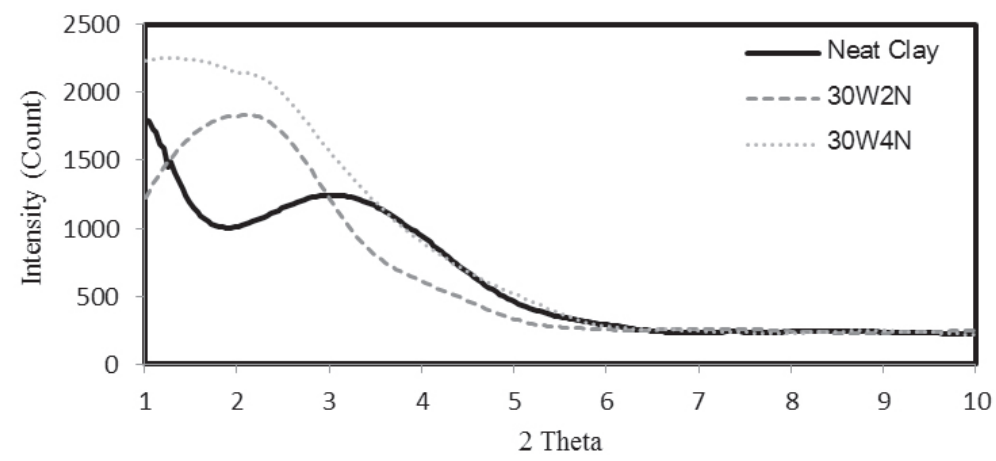

Figure 5. XRD patterns of nanoclay content at $1^{\circ}$ to $10^{\circ}$. 


\section{CONCLUSIONS}

The effect of weathering on the physical and mechanical properties of the WPC containing different nanoclay levels has been investigated. The main observations drawn from this study are summarized as follows:

The general trend of WPC weathering shows that surface oxidation increased after exposure. However after 500,1500 , and $2000 \mathrm{~h}$ of weathering the nanocomposites containing $2 \mathrm{wt} \%$ of nanoclay showed less carbonyl index as compared to other samples.

The water absorption of control and weathered WPCs was increased after 30 days water exposure. Addition of nanoclay to the WPCs improved the water absorption. However water absorption of weathered nanoWPCs was less than that of weathered WPCs.

MOE values of WPCs were improved by the addition of nanoclay to the composite. However weathering decreased the MOE values of WPC and nanoWPC. Although weathering conditions can degrade the MOE of WPCs, good dispersion of nanoclay in the HDPE matrix to some extent can hide the negative effect of weathering.

FTIR spectroscopy also revealed that using of $2 \mathrm{wt} \%$ of nanoclay decreased the forming of carbonyl groups meaning that less degradation has occurred.

XRD study indicated a better intercalation in WPC loaded with $2 \mathrm{wt} \%$ nanoclay compared to WPC loaded with $4 \mathrm{wt} \%$ nanoclay. The agglomeration of nanoclay might be responsible for this phenomenon.

The addition of nanoclay up to $2 \mathrm{wt} \%$ can provide indirect protection against the deleterious effects of weathering and thereby less drop of MOE through decreasing of water absorption and its oxidative role has occurred.

\section{REFERENCES}

Adhikary, K.B.; Pang, S.; Staiger, M. 2009. Accelerated ultraviolet weathering of recycled polypropylene sawdust composites. Thermoplastic Composite Materials 22(6):661-679.

Alexandre, B.; Marais, S.; Langevin, D.; Mederic, P.; Aubry, T. 2006. Nanocomposite-based polyamide 12/montmorillonite: relationships between structures and transport properties. Desalination 199(1):164-166.

Ashori, A.; Nourbakhsh, A. 2011. Preparation and characterization of polypropylene/wood flour/ nanoclay composites, European Journal of Wood and Wood Products 69(4):663-666.

Ashori, A.; Nourbakhsh, A. 2009. Effects of nanoclay as a reinforcement filler on the physical and mechanical properties of wood based composite. Compos Mater 43(18):1869-1875.

Belgacem, M.N.; Bataille, P.; Sapieha, S. 1994. Effect of corona modification on the mechanical properties of polypropylene/cellulose composites. J Appl Polym Sci 53(4):379-385.

Candan, Z.; Akbulut, T. 2015. Physical and mechanical properties of nanoreinforced particleboard composites. Maderas-Cienc Tecnol 17(2):319-334. 
Colom, X.; Carrillo, F.; Nogues, F.; Garriga, P. 2003. Structural analysis of photodegraded wood by means of FTIR spectroscopy. Polymer Degradation and Stability 80(3):543-549.

Eshraghi, A.; Khademieslam, H.; Ghasemi, I.; Talaiepoor, M. 2013. Effect of weathering on the properties of hybrid composite based on polyethylene, wood flour, and nanoclay. BioResources $8(1): 201-210$

Faruk, O.; Matuana, L.M. 2008. Nanoclay reinforced HDPE as a matrix for wood-plastic composites. Composites Science and Technology 68(9):2073-2077.

Ghasemi, I.; Kord, B. 2009. Long-term water absorption behaviour of polypropylene/wood flour/ organoclay hybrid nanocomposite. Iranian Polymer Journal 18(9):683-691.

Grigoriadou, I.; Paraskevopoulos, K.M.; Chrissafis, K.; Pavlidou, E. Stamkopoulos, T.G. ; Bikiaris, D. 2011. Effect of different nanoparticles on HDPE UV stability. Polymer Degradation and Stability 96(1):151-163.

Hemmasi, A.H.; Khademi-Eslam, H.; Talaiepoor, M.; Kord, B.; Ghasemi, I. 2010. Effect of nanoclay on the mechanical and morphological properties of wood polymer nanocomposite. Reinforced Plastics and Composites 29(7):964-971.

Khonsari, A.; Taghiyari H.R.; Karimi, A.; Tajvidi, M. 2015. Study on the effects of wood flour geometry on physical and mechanical properties of wood-plastic composites. Maderas-Cienc Tecnol 17(3): 545-558.

Kord, B.; Hemmasi, A.; Ghasemi, I. 2011. Properties of PP/wood flour/organomodified montmorillonite nanocomposites. Wood Sci Technol 45(1):111-119.

Lee, H.; Kim, D.S. 2009. Preparation and physical properties of wood/polypropylene/clay nanocomposites. Applied Polymer Science 111(6):2769-2776.

Lundin, T.; Cramer, S.M.; Falk, R. H.; Felton, C. 2004. Accelerated weathering of natural fiberfilled polyethylene composites. Materials in Civil Engineering 16(6):547-555.

Pascual, J.; Fages, E.; Fenollar, O.; García, D.; Balart, R. 2009. Influence of the compatibilizer/ nanoclay ratio on final properties of polypropylene matrix modified with montmorillonite-based organoclay. Polymer Bulletin 62(3):367-380.

Roy, P. K.; Surekha, P.; Raman, R.; Rajagopal, C. 2009. Investigating the role of metal oxidation state on the degradation behaviour of LDPE. Polymer Degradation and Stability 94(7):1033-1039.

Samariha, A.; Hemmasi, A.H.; Ghasemi, I.; Bazyar, B.; Nemati, M. 2015. Effect of nanoclay contents on properties of bagasse flour/reprocessed high density polyethylene/nanoclay composites. Maderas-Cienc Tecnol 17(3):637-646.

Stark, N. 2001. Influence of moisture absorption on mechanical properties of wood flour polypropylene composites. Thermoplastic Composite Materials 14(5):421-432.

Stark, N. 2006. Effect of weathering cycle and manufacturing method on performance of wood flour and high density polyethylene composites. Applied Polymer Science 100(4):3131-3140. 
Stark, N.; Matuana, L. M. 2004. Surface chemistry changes of weathered HDPE/ wood flour composites studied by XPS and FTIR spectroscopy. Polym Degrad Stab 86(1):1-9.

Stark, N. ; Matuana, L.M.; Clemons, C.M. 2003. Effect of processing method on accelerated weathering of wood flour-HDPE composites," Proceedings of the 7th International Conference on Woodfiber-Plastic Composites, 79-87.

Vazquez, M.R.; Liauw, C.M.; Allen, N.S.; Edge, M.; Fontan, E. 2006. Degradation and stabilisation of poly(ethylene-stat-vinyl acetate): 1 - Spectroscopic and rheological examination of thermal and thermo-oxidative degradation mechanisms. Polymer Degradation and Stability 91(1):154164. 